\title{
Associação entre arquitetura de planta e produtividade de grãos em progênies de feijoeiro de porte ereto e prostrado
}

\author{
Camila Andrade Silva(1), Ângela de Fátima Barbosa $\mathrm{Abreu}^{(2)}$ e Magno Antonio Patto Ramalho(1)
} (1)Universidade Federal de Lavras, Departamento de Biologia, Caixa Postal 3.037, CEP 37200-000 Lavras, MG. E-mail: camilaagro01@yahoo.com.br,
magnoapr@ufla.br (2)Embrapa Arroz e Feijão, Caixa Postal 3037, CEP 37200-000 Lavras, MG. E-mail: afbabreu@ufla.br

Resumo - O objetivo deste trabalho foi avaliar se progênies de feijoeiro de porte ereto e prostrado de um mesmo grupo gênico apresentam o mesmo potencial produtivo. Realizaram-se cruzamentos entre uma cultivar de porte prostrado e três de porte ereto, e foram obtidas três populações até a geração $\mathrm{F}_{5}$, quando foi realizada a seleção de plantas eretas e prostradas de cada população. Essas plantas foram avaliadas em experimentos distintos. Nas gerações $F_{5: 6}, F_{5: 7}$ e $F_{5: 8}$, foram avaliados o porte da planta, com notas de 1 (ereta) a 9 (prostrada), e a produtividade de grãos. Foram estimados os ganhos esperados quanto à seleção para porte e a resposta correlacionada à produtividade de grãos, além dos ganhos quanto à seleção para produtividade de grãos e a resposta correlacionada ao porte. A correlação entre melhor porte e produtividade de grãos foi pequena e negativa. É possível selecionar progênies de feijoeiro, simultaneamente, para obtenção de maior produtividade e de melhor arquitetura.

Termos para indexação: Phaseolus vulgaris, ganho genético, melhoramento de feijão-comum, porte, resposta correlacionada, seleção.

\section{Plant architecture and grain yield in common bean progenies with erect and prostrate plant habit}

\begin{abstract}
The objective of this work was to evaluate if progenies with erect and prostrate plant habit, from the same genetic pool, have the same yield potential. Crosses between a prostrate and three erect cultivars were made yielding three populations up to the $\mathrm{F}_{5}$ generation. In this generation, erect and prostrate plants from each population were selected and evaluated in separate experiments. Generations $\mathrm{F}_{5: 6}, \mathrm{~F}_{5: 7}$ and $\mathrm{F}_{5: 8}$ were evaluated for plant architecture, in a scale from 1 (erect) to 9 (prostrate) and for grain yield. The expected gain for selection for plant habit and the correlated response in grain yield, as well as gain from selection for grain yield with the correlated response in plant habit were estimated. The correlation between selection for better plant habit and grain yield was low and negative. It is possible to select common bean progenies simultaneously for yield and plant habit.

Index terms: Phaseolus vulgaris, genetic gain, common bean breeding, plant habit, correlated response, selection.
\end{abstract}

\section{Introdução}

A cultura do feijoeiro tem passado por grandes mudanças, em razão do maior emprego de tecnologia, e tem se tornado de interesse para grandes produtores rurais. A demanda por cultivares mais produtivas, com arquitetura de planta que facilite os tratos culturais e a colheita mecanizada, é bastante elevada. Plantas com o porte mais ereto têm sido uma das principais exigências tanto dos empresários rurais quanto dos agricultores familiares.

Informações sobre o controle genético de caracteres relacionados ao porte das plantas do feijoeiro não são novidade. Teixeira et al. (1999) avaliaram vários caracteres da planta e constataram que o comprimento de entrenós foi responsável pela maior parte da variação na arquitetura da planta. A predominância de genes com efeito aditivo no controle genético da altura da planta e do comprimento da haste principal também foi observada por Nienhuis \& Singh (1986) e Santos \& Vencovsky (1986). Singh et al. (1991) verificaram que o comprimento da haste principal é controlado por um único gene, cujo alelo dominante é responsável por haste longa. Entretanto, a presença de outros genes com menor efeito não pode ser descartada.

Uma estratégia que tem sido amplamente utilizada pelos programas de melhoramento, para avaliar a 
arquitetura da planta, é o emprego de escala de notas (Collicchio et al., 1997; Teixeira et al., 1999; Cunha et al., 2005; Menezes Júnior et al., 2008). Teixeira et al. (1999) verificaram que, apesar da acentuada influência do ambiente na expressão do porte, as estimativas dos parâmetros genéticos evidenciaram a possibilidade de sucesso com a seleção, especialmente se esta for realizada após a avaliação em várias gerações ou em diversos ambientes. Mendes et al. (2009) constataram que é possível selecionar populações segregantes superiores, considerando-se simultaneamente a produtividade de grãos e as notas de porte e de acamamento.

Plantas com arquitetura ereta têm menos ramificações, nós e gemas e, portanto, espera-se que seu potencial produtivo seja inferior ao de plantas prostradas (Nienhuis \& Singh, 1986; Teixeira et al., 1999). Alves et al. (2001) e Dawo et al. (2007) argumentaram que há correlação negativa entre produtividade e porte ereto, o que é considerado um empecilho na obtenção de cultivares modernas. Contudo, esses trabalhos têm comparado cultivares de diferentes origens e grupos genéticos, o que torna impraticável isolar os efeitos do potencial produtivo das linhagens dos efeitos relativos à morfologia das plantas. Além disso, em programas de melhoramento mais antigos, não se deu ênfase à seleção para a arquitetura das plantas, e as cultivares com hábito de crescimento prostrado foram submetidas a mais ciclos de seleção para a produtividade do que as eretas, obtidas mais recentemente.

O objetivo deste trabalho foi avaliar se progênies de porte ereto apresentam o mesmo potencial produtivo que progênies de porte prostrado, quando ambas são oriundas de uma mesma população segregante, ou seja, obtidas de um mesmo grupo gênico.

\section{Material e Métodos}

Os experimentos foram realizados na área experimental do Departamento de Biologia da Universidade Federal de Lavras (Ufla), Lavras, MG, a $918,8 \mathrm{~m}$ de altitude, $21^{\circ} 14$ 'S e $45^{\circ} 59^{\prime} \mathrm{W}$.

Foram realizados cruzamentos entre a cultivar BRSMG Majestoso, de hábito de crescimento III, porte de planta prostrado e cor de grão bege com rajas marrons, e três cultivares de hábito de crescimento II e porte de planta ereto: BRS Horizonte (bege com rajas marrons), BRS Supremo (preta) e BRS Valente (preta). As populações obtidas foram conduzidas pelo método da população até a geração $\mathrm{F}_{5}$. Nessa geração (safra das "águas" 2007/2008), foram selecionadas 64 plantas eretas e 64 prostradas de cada população. As progênies selecionadas foram avaliadas juntamente com os genitores, nas gerações $\mathrm{F}_{5: 6}, \mathrm{~F}_{5: 7}$ e $\mathrm{F}_{5: 8}$ (Tabela 1). As progênies foram avaliadas em dois experimentos distintos - um com as progênies de porte ereto e outro com as prostradas -, para evitar possíveis efeitos de competição ocasionados pela diferença na arquitetura das plantas.

A avaliação do porte das plantas foi realizada por meio de escala de notas (Collicchio et al., 1997) que variaram de 1 a 9, em que 1 indica as plantas totalmente eretas e 9 as totalmente prostradas. A produtividade de grãos foi obtida em gramas por parcela e transformada para quilogramas por hectare.

A partir dos dados provenientes da avaliação do porte das plantas, realizada na geração $\mathrm{F}_{5: 6}$, foram selecionadas as 117 progênies mais eretas do experimento de plantas eretas (39 de cada população) e as 117 mais prostradas do experimento de plantas prostradas. Da mesma forma, na geração $\mathrm{F}_{5: 7}$, foram selecionadas as 45 progênies mais eretas do experimento de plantas eretas ( 15 de cada população) e as 45 mais prostradas do experimento de plantas prostradas que foram avaliadas na geração $F_{5: 8}$.

Os dados de produtividade de grãos $\left(\mathrm{kg} \mathrm{ha}^{-1}\right)$ e porte das plantas foram submetidos à análise de variância por geração (safra), tendo-se considerado todos os efeitos do modelo como aleatórios, exceto a média, nas gerações $\mathrm{F}_{5: 6}$ e $\mathrm{F}_{5: 7}$. Na geração $\mathrm{F}_{5: 8}$, os efeitos de progênies e a média foram considerados como fixos. Posteriormente, foi efetuada a análise de variância agrupada, tendo-se utilizado as testemunhas comuns (genitores), conforme Ramalho et al. (1993). Também foi realizada a análise de variância conjunta das gerações, com as médias ajustadas dos tratamentos comuns às três gerações de avaliação. As análises foram realizadas pelo programa SAS versão 9.0 (SAS Institute, 2000).

Tabela 1. Detalhes experimentais da avaliação quanto ao porte e produção de progênies de porte ereto e prostrado, oriundas de três populações segregantes de feijoeiro, nas gerações $\mathrm{F}_{5: 6}, \mathrm{~F}_{5: 7}$ e $\mathrm{F}_{5: 8}$.

\begin{tabular}{lccc}
\hline Dado experimental & $\mathrm{F}_{5: 6}$ & $\mathrm{~F}_{5: 7}$ & $\mathrm{~F}_{5: 8}$ \\
\hline Número de progênies & 64 & 39 & 15 \\
Safra & Seca de 2008 & Inverno de 2008 & Águas 2008/2009 \\
Delineamento & Látice 14x14 & Látice 11x11 & Látice 7x7 \\
Repetições & 2 & 3 & 3 \\
Parcela & Uma linha de 2 $\mathrm{m}$ & Duas linhas de 2 $\mathrm{m}$ & Duas linhas de 2 m \\
\hline
\end{tabular}


Foram estimados os seguintes parâmetros genéticos e fenotípicos nas gerações $\mathrm{F}_{5: 6}$ e $\mathrm{F}_{5: 7}$ : variância genética entre progênies $\left(\sigma_{\mathrm{p}}^{2}\right)$ por geração, tendo-se considerado separadamente progênies eretas e prostradas para cada população; intervalos de confiança associados às estimativas das variâncias genéticas entre progênies; herdabilidade no sentido restrito $\left(\mathrm{h}^{2} \mathrm{r}\right)$, na média das progênies por geração, tendo-se considerado separadamente progênies eretas e prostradas de cada população e os limites inferiores (LI) e superiores (LS) das estimativas de herdabilidade (Knapp et al., 1985).

Estimou-se o ganho esperado com a seleção (GS) na média das progênies, tanto em relação à nota de porte quanto à produtividade de grãos, tendose considerado a intensidade de seleção de $10 \%$. Foi estimada também a resposta correlacionada à produtividade de grãos, para a seleção efetuada quanto à nota de porte e vice-versa. As estimativas foram obtidas a partir da expressão de ganho com a seleção, apresentada por Ramalho et al. (1993).

\section{Resultados e Discussão}

Considerando-se como de porte ereto as progênies com médias de notas de porte até 4,5, verifica-se que as médias das progênies eretas ficaram dentro do intervalo proposto (Tabela 2). Para as progênies prostradas, o mesmo comportamento foi observado, o que demonstra, em princípio, que a seleção visual quanto à arquitetura de planta, realizada na geração $\mathrm{F}_{5}$, foi eficiente na discriminação dessa característica.

A existência de variabilidade em arquitetura de planta, na geração $\mathrm{F}_{5: 6}$, pode ser observada pelas estimativas da $h^{2} r$ que, para todas as progênies, exceto as prostradas da população 'BRSMG Majestoso' $\mathrm{x}$ 'BRS Supremo', apresentaram limite inferior positivo, o que indica que $a \mathrm{~h}^{2} \mathrm{r}$ foi diferente de zero (Tabela 3 ). $\mathrm{Na}$ geração $\mathrm{F}_{5: 7}$, apenas entre as progênies eretas da população 'BRSMG Majestoso' x 'BRS Horizonte', o limite inferior da $\mathrm{h}^{2} \mathrm{r}$ foi negativo.

As progênies que apresentaram pior desempenho médio em relação às notas de porte, em todas as gerações, foram as da população 'BRSMG Majestoso' x 'BRS Supremo' (Tabela 2). Esse desempenho não era esperado, pois um dos genitores ('BRS Supremo') se destacou pelo melhor porte entre as cultivares existentes no mercado (Abreu et al., 2008).
Tanto as progênies eretas quanto as prostradas foram reunidas em um mesmo grupo de produtividade de grãos, pelo teste de Scott \& Knott (Tabela 2). Considerando-se as médias de porte dessas progênies, nota-se que foram formados dois grupos, em todas as populações, o que evidencia a possibilidade de se obter progênies de porte ereto com produtividade equivalente ao das prostradas, o que também foi observado por Cunha et al. (2005) e Menezes Júnior et al. (2008).

As progênies derivadas do cruzamento 'BRSMG Majestoso' x 'BRS Valente' apresentaram a maior produtividade de grãos na média das três gerações, nos dois experimentos (Tabela 2). Segundo Silva et al. (2008), o genitor 'BRS Valente' é uma cultivar

Tabela 2. Médias das 15 progênies comuns às gerações $\mathrm{F}_{5: 6}, \mathrm{~F}_{5: 7}$ e $\mathrm{F}_{5: 8}$, oriundas de três populações segregantes de feijoeiro, quanto ao porte da planta e à produtividade de grãos $^{(1)}$.

\begin{tabular}{|c|c|c|c|c|c|c|}
\hline \multirow[t]{2}{*}{ Progênie } & \multicolumn{2}{|c|}{$\begin{array}{c}\text { BRSMG Majestoso } \\
\text { x BRS Horizonte }\end{array}$} & \multicolumn{2}{|c|}{$\begin{array}{c}\text { BRSMG Majestoso } \\
\text { x BRS Supremo }\end{array}$} & \multicolumn{2}{|c|}{$\begin{array}{c}\text { BRSMG Majestoso } \\
\text { x BRS Valente }\end{array}$} \\
\hline & Prostrada & Ereta & Prostrada & Ereta & Prostrada & Ereta \\
\hline & \multicolumn{6}{|c|}{ Porte da planta (notas de 1 a 9) } \\
\hline 1 & $5,4 \mathrm{~b}$ & $2,5 \mathrm{a}$ & $6,0 \mathrm{~b}$ & $3,4 \mathrm{a}$ & $6,5 b$ & $3,4 \mathrm{a}$ \\
\hline 2 & $5,1 b$ & $2,8 \mathrm{a}$ & $6,1 b$ & $3,7 \mathrm{a}$ & $6,8 b$ & $3,2 \mathrm{a}$ \\
\hline 3 & $4,9 \mathrm{~b}$ & $2,9 \mathrm{a}$ & $6,2 b$ & $2,9 a$ & $6,3 b$ & $4,2 \mathrm{a}$ \\
\hline 4 & $5,1 b$ & $2,8 \mathrm{a}$ & $6,5 b$ & $3,3 \mathrm{a}$ & $6,3 b$ & $2,9 \mathrm{a}$ \\
\hline 5 & $5,3 b$ & $2,3 a$ & $6,3 b$ & $3,6 \mathrm{a}$ & $6,2 b$ & $2,8 \mathrm{a}$ \\
\hline 6 & $6,6 b$ & $3,1 \mathrm{a}$ & $6,4 \mathrm{~b}$ & $3,7 \mathrm{a}$ & $6,1 b$ & $2,9 \mathrm{a}$ \\
\hline 7 & $5,4 \mathrm{~b}$ & $2,4 \mathrm{a}$ & $6,8 b$ & $4,1 \mathrm{a}$ & $6,1 \mathrm{~b}$ & $2,4 a$ \\
\hline 8 & $5,0 \mathrm{~b}$ & $2,7 \mathrm{a}$ & $6,7 b$ & $3,1 \mathrm{a}$ & $4,9 \mathrm{~b}$ & $3,0 \mathrm{a}$ \\
\hline 9 & $6,8 \mathrm{~b}$ & $2,2 \mathrm{a}$ & $6,4 \mathrm{~b}$ & $3,2 \mathrm{a}$ & $6,3 b$ & $3,6 \mathrm{a}$ \\
\hline 10 & $5,3 b$ & $3,5 \mathrm{a}$ & $7,2 \mathrm{~b}$ & $2,9 \mathrm{a}$ & $6,3 b$ & $3,1 \mathrm{a}$ \\
\hline 11 & $5,6 \mathrm{~b}$ & $3,5 \mathrm{a}$ & $6,5 b$ & $2,6 \mathrm{a}$ & $6,6 \mathrm{~b}$ & $3,2 \mathrm{a}$ \\
\hline 12 & $5,6 b$ & $3,7 \mathrm{a}$ & $6,5 b$ & $2,9 a$ & $6,7 \mathrm{~b}$ & $2,7 \mathrm{a}$ \\
\hline 13 & $6,4 \mathrm{~b}$ & $3,0 \mathrm{a}$ & $7,2 \mathrm{~b}$ & $2,9 a$ & $6,8 \mathrm{~b}$ & $1,7 \mathrm{a}$ \\
\hline 14 & $5,8 b$ & $2,9 a$ & $6,8 \mathrm{~b}$ & $3,9 a$ & $6,6 \mathrm{~b}$ & $2,8 \mathrm{a}$ \\
\hline 15 & $5,4 \mathrm{~b}$ & $3,1 \mathrm{a}$ & $6,2 b$ & $2,8 \mathrm{a}$ & $5,7 \mathrm{~b}$ & $2,1 \mathrm{a}$ \\
\hline Média & $4,9 \mathrm{D}$ & $2,7 \mathrm{~A}$ & $6,6 \mathrm{~F}$ & $3,7 \mathrm{C}$ & $5,5 \mathrm{E}$ & $3,3 \mathrm{~B}$ \\
\hline & & \multicolumn{5}{|c|}{ Produtividade de grãos $\left(\mathrm{kg} \mathrm{ha}^{-1}\right)$} \\
\hline 1 & $2.314 \mathrm{a}$ & $2.144 \mathrm{a}$ & $2.481 \mathrm{a}$ & $2.214 \mathrm{a}$ & $1.839 \mathrm{a}$ & $2.253 \mathrm{a}$ \\
\hline 2 & $2.693 a$ & $2.156 \mathrm{a}$ & $2.902 \mathrm{a}$ & $2.242 \mathrm{a}$ & $2.406 \mathrm{a}$ & $2.242 \mathrm{a}$ \\
\hline 3 & $2.296 \mathrm{a}$ & $2.536 \mathrm{a}$ & $1.819 \mathrm{a}$ & $2.156 \mathrm{a}$ & $2.756 \mathrm{a}$ & $2.556 \mathrm{a}$ \\
\hline 4 & $2.052 \mathrm{a}$ & $2.104 \mathrm{a}$ & $2.139 \mathrm{a}$ & $1.681 \mathrm{a}$ & $2.411 \mathrm{a}$ & $2.447 \mathrm{a}$ \\
\hline 5 & $2.185 \mathrm{a}$ & $2.303 a$ & $2.558 \mathrm{a}$ & $2.119 \mathrm{a}$ & $2.669 \mathrm{a}$ & $2.385 \mathrm{a}$ \\
\hline 6 & $2.758 \mathrm{a}$ & $2.461 \mathrm{a}$ & $2.240 \mathrm{a}$ & $2.089 \mathrm{a}$ & $2.694 \mathrm{a}$ & $1.774 \mathrm{a}$ \\
\hline 7 & $2.640 \mathrm{a}$ & $2.180 \mathrm{a}$ & $2.303 \mathrm{a}$ & $1.694 \mathrm{a}$ & $2.814 \mathrm{a}$ & $2.181 \mathrm{a}$ \\
\hline 8 & $2.207 \mathrm{a}$ & $2.220 \mathrm{a}$ & $2.547 \mathrm{a}$ & $1.888 \mathrm{a}$ & $2.516 \mathrm{a}$ & $2.483 a$ \\
\hline 9 & $2.503 \mathrm{a}$ & $1.949 \mathrm{a}$ & $2.522 \mathrm{a}$ & $2.144 \mathrm{a}$ & $2.656 \mathrm{a}$ & $3.242 \mathrm{a}$ \\
\hline 10 & $2.300 \mathrm{a}$ & $1.780 \mathrm{a}$ & $2.764 a$ & $2.022 \mathrm{a}$ & $2.531 \mathrm{a}$ & $2.644 a$ \\
\hline 11 & $1.960 \mathrm{a}$ & $2.439 a$ & $2.486 \mathrm{a}$ & $2.392 \mathrm{a}$ & $2.683 a$ & $2.293 \mathrm{a}$ \\
\hline 12 & $2.554 \mathrm{a}$ & $2.214 \mathrm{a}$ & $2.442 \mathrm{a}$ & $1.892 \mathrm{a}$ & $2.186 \mathrm{a}$ & $1.567 \mathrm{a}$ \\
\hline 13 & $2.690 \mathrm{a}$ & $2.186 \mathrm{a}$ & $2.528 \mathrm{a}$ & $2.083 a$ & $2.308 \mathrm{a}$ & $2.017 \mathrm{a}$ \\
\hline 14 & $2.339 \mathrm{a}$ & $1.914 \mathrm{a}$ & $2.328 \mathrm{a}$ & $1.782 \mathrm{a}$ & $2.342 \mathrm{a}$ & $2.428 \mathrm{a}$ \\
\hline 15 & $2.217 \mathrm{a}$ & $2.378 \mathrm{a}$ & $2.399 \mathrm{a}$ & $1.415 \mathrm{a}$ & $2.436 \mathrm{a}$ & $2.311 \mathrm{a}$ \\
\hline Média & $2.298 \mathrm{C}$ & $2.210 \mathrm{C}$ & $2.393 \mathrm{~B}$ & $2.350 \mathrm{~B}$ & $2.581 \mathrm{~A}$ & $2.498 \mathrm{~A}$ \\
\hline
\end{tabular}

${ }^{(1)}$ Médias seguidas de letras iguais, minúsculas nas colunas e maiúsculas nas linhas, não diferem entre si pelo teste de Scott \& Knott, a 5\% de probabilidade. 
com alto potencial em programas de melhoramento que visam a melhoria da arquitetura de plantas. Mendes et al. (2009) observaram que o cruzamento 'BRS Supremo' x 'BRS Valente' apresentou a maior capacidade específica de combinação para porte ereto. No presente trabalho, esse cruzamento também se mostrou adequado na associação de alta produtividade e porte ereto.

As estimativas dos ganhos esperados com a seleção realizada isoladamente, para cada caráter (porte da planta e produtividade), e a resposta correlacionada em um caráter com a seleção realizada no outro estão apresentadas na Tabela 4. Na geração $\mathrm{F}_{5: 6}$ de progênies derivadas do cruzamento 'BRSMG Majestoso' x 'BRS Supremo', foram observados ganhos de até $37,74 \%$ na diminuição das médias das notas de porte e, na geração $\mathrm{F}_{5: 7}$ de progênies derivadas do cruzamento 'BRSMG Majestoso' x 'BRS Horizonte', os ganhos alcançaram $26,73 \%$. É importante ressaltar que todas as progênies selecionadas eram eretas, o que confirma, mais uma vez, a eficiência da seleção visual quanto à arquitetura da planta.

Também foram obtidos os ganhos esperados e as respostas correlacionadas à seleção, ao se considerarem as três populações conjuntamente. Os ganhos alcançaram $27 \%$ na diminuição das notas de porte da planta. É interessante notar que, entre as progênies selecionadas nas duas gerações, mais de 50\% eram da população 'BRSMG Majestoso' x 'BRS Horizonte'. Na Tabela 2, pode-se observar que essa população, em média, apresentou as menores notas de porte, o que é uma indicação de que há maiores chances de sucesso na seleção, quando se considera apenas o porte, nessa população.

Nas estimativas das respostas correlacionadas, verificou-se que, quando a seleção foi realizada com base no porte, na maioria das populações houve decréscimo, embora de pequena magnitude, na média de produtividade (Tabela 4). Quando a seleção foi realizada levando-se em consideração as maiores médias de produtividade, os ganhos com a seleção foram de até $17,62 \%$, e a população derivada do cruzamento 'BRSMG Majestoso' x 'BRS Supremo' foi a que teve maiores ganhos, nas gerações $F_{5: 6}$ e $F_{5: 7}$ em que foram obtidas essas estimativas. Isto pode ser explicado pela maior estimativa de herdabilidade obtida para essa população (Tabela 3). Pelos resultados da resposta correlacionada, verificou-se a tendência de piorar a arquitetura de plantas, embora na média de todas as populações a resposta correlacionada tenha sido de pequena magnitude apenas $1 \%$. Resultados semelhantes foram relatados por Collicchio et al. (1997) e Cunha et al. (2005). Isto ocorre porque a correlação (r) entre a produtividade de grãos e a nota de porte é quase sempre positiva (Tabela 5). As estimativas de correlação, embora significativas em alguns casos, não foram de grande magnitude, o que é uma evidência de que é possível identificar progênies produtivas e com menor nota de porte, ao

Tabela 3. Estimativas da variância genética $\left(\sigma_{\mathrm{p}}^{2}\right)$ e herdabilidade no sentido restrito $\left(\mathrm{h}^{2} \mathrm{r}\right)$, quanto à arquitetura de plantas (notas de 1 a 9) e produtividades de grãos $\left(\mathrm{kg} \mathrm{ha}^{-1}\right)$ das progênies $\mathrm{F}_{5: 6}$ e $\mathrm{F}_{5: 7}$, selecionadas quanto ao porte ereto e prostrado, oriundas de três populações segregantes do feijoeiro ${ }^{(1)}$.

\begin{tabular}{|c|c|c|c|c|}
\hline \multirow[t]{2}{*}{ População } & \multicolumn{2}{|l|}{$\mathrm{F}_{5: 6}$} & \multicolumn{2}{|l|}{$\mathrm{F}_{5: 7}$} \\
\hline & $\sigma_{p}^{2}$ & $\mathrm{~h}^{2} \mathrm{r}(\%)$ & $\sigma_{p}^{2}$ & $\mathrm{~h}^{2} \mathrm{r}(\%)$ \\
\hline & \multicolumn{4}{|c|}{ Porte de progênies prostradas } \\
\hline BRSMG Majestoso x BRS Horizonte & $0,36(0,29-0,58)$ & $41,18(11,78-58,67)$ & $0,50(0,38-0,79)$ & $65,00(41,20-77,42)$ \\
\hline BRSMG Majestoso x BRS Supremo & $0,14(0,11-0,21)$ & $20,29(19,54-43,99)$ & $0,18(0,14-0,30)$ & $40,00(0,18-61,53)$ \\
\hline \multirow[t]{2}{*}{ BRSMG Majestoso x BRS Valente } & $0,34(0,25-0,50)$ & $37,85(6,80-56,33)$ & $0,19(0,14-0,30)$ & $41,30(1,27-62,10)$ \\
\hline & \multicolumn{4}{|c|}{ Produtividade de progênies prostradas } \\
\hline BRSMG Majestoso $\mathrm{x}$ BRS Horizonte & $277,71(208,28-416,57)$ & $0,17(-49,72-29,85)$ & $18940,57(14394,83-29989,24)$ & $7,80(-55,87-40,15)$ \\
\hline BRSMG Majestoso x BRS Supremo & $84678,71(63509,00-127018,07)$ & $33,63(0,47-53,37)$ & $137548,90(104537,16-217785,76)$ & $38,06(-4,71-59,80)$ \\
\hline \multirow[t]{2}{*}{ BRSMG Majestoso x BRS Valente } & $41479,21(31109,40-62218,82)$ & $19,89(-20,15-43,71)$ & $41228,23(31333,45-65278,03)$ & $15,56(-42,76-45,18)$ \\
\hline & \multicolumn{4}{|c|}{ Porte de progênies eretas } \\
\hline BRSMG Majestoso x BRS Horizonte & $1,10(0,82-1,64)$ & $66,57(49,86-76,51)$ & $0,03(0,02-0,05)$ & $10,00(-51,97-41,65)$ \\
\hline BRSMG Majestoso x BRS Supremo & $1,04(0,78-1,56)$ & $65,30(47,96-75,62)$ & $0,27(0,21-0,43)$ & $50,00(16,51-67,94)$ \\
\hline BRSMG Majestoso x BRS Valente & $0,71(0,53-1,07)$ & $56,35(34,54-69,33)$ & $0,19(0,14-0,30)$ & $41,30(1,99-62,37)$ \\
\hline & \multicolumn{4}{|c|}{ Produtividade de progênies eretas } \\
\hline BRSMG Majestoso x BRS Horizonte & - & - & $643,90(489,36-1019,51)$ & $0,29(-68,57-35,28)$ \\
\hline BRSMG Majestoso x BRS Supremo & $38884,2(29163,16-58326,32)$ & $18,88(-21,66-43,00)$ & $104371,57(79332,40-165254,99)$ & $31,80(-15,30-55,73)$ \\
\hline BRSMG Majestoso x BRS Valente & $98347,21(73760,41-147520,82)$ & $37,00(5,60-55,77)$ & $110600,57(84056,43-175117,57)$ & $33,10(-13,16-56,55)$ \\
\hline
\end{tabular}

Pesq. agropec. bras., Brasília, v.44, n.12, p.1647-1652, dez. 2009 
mesmo tempo, uma vez que a correlação entre o porte e a produtividade de grãos não foi expressiva.

Entre as progênies selecionadas quanto à produtividade de grãos na geração $F_{5: 6}$, aproximadamente $50 \%$ eram eretas, indício de que também foi possível selecionar plantas com altas médias de produtividade de grãos nessas progênies. Quando a seleção foi realizada sem a discriminação de população, os ganhos alcançaram 11\% (geração $\mathrm{F}_{5: 6}$ ), e a maioria das progênies selecionadas pertencia à população 'BRSMG Majestoso' x'BRS Valente'. Porém, nesse caso, as notas de porte aumentaram até $8 \%$, o que mostra que pode ocorrer dificuldade na seleção, quando se considera apenas um caráter. Portanto, uma alternativa é utilizar índices de seleção, para que sejam obtidos ganhos satisfatórios para todos os caracteres de interesse simultaneamente, conforme preconizado por Cunha et al. (2005), Menezes Júnior et al. (2008) e Mendes et al. (2009).

Tabela 4. Estimativas dos ganhos esperados com a seleção (GS\%) quanto à arquitetura de planta (notas de 1 a 9), produtividade de grãos $\left(\mathrm{kg} \mathrm{ha}^{-1}\right)$ e resposta correlacionada (RC\%) de produtividade e arquitetura de planta, nas progênies $\mathrm{F}_{5: 6}$ e $\mathrm{F}_{5: 7}$, oriundas de três populações segregantes de feijoeiro.

\begin{tabular}{|c|c|c|c|c|}
\hline Estimativa & $\begin{array}{c}\text { BRSMG } \\
\text { Majestoso } \\
\text { x BRS Horizonte }\end{array}$ & $\begin{array}{c}\text { BRSMG } \\
\text { Majestoso } \\
\text { x BRS Supremo }\end{array}$ & $\begin{array}{c}\text { BRSMG } \\
\text { Majestoso } \\
\text { x BRS Valente } \\
\end{array}$ & Geral \\
\hline & \multicolumn{4}{|c|}{ Progênie $\mathrm{F}_{5: 6}$} \\
\hline $\mathrm{GS}_{\text {porte }}(\%)$ & $-35,76$ & $-37,74$ & $-33,16$ & $-27,00$ \\
\hline $\mathrm{RC}_{\text {produtividade }}(\%)$ & $-0,01$ & $-4,50$ & $-4,24$ & $-3,00$ \\
\hline $\mathrm{GS}_{\text {produtividade }}(\%)$ & 0,06 & 17,62 & 3,37 & 11,00 \\
\hline $\mathrm{RC}_{\text {porte }}(\%)$ & 5,30 & 11,08 & 15,48 & 1,00 \\
\hline \multicolumn{5}{|c|}{ Progênie $\mathrm{F}_{5: 7}$} \\
\hline $\mathrm{GS}_{\text {porte }}(\%)$ & $-26,73$ & $-21,90$ & $-18,23$ & $-18,00$ \\
\hline $\mathrm{RC}_{\text {produtividade }}(\%)$ & $-0,14$ & $-5,58$ & $-2,14$ & $-1,30$ \\
\hline $\mathrm{GS}_{\text {produtividade }}(\%)$ & 2,36 & 16,02 & 12,33 & 7,50 \\
\hline $\mathrm{RC}_{\text {porte }}(\%)$ & 14,07 & 14,30 & 7,00 & 8,00 \\
\hline
\end{tabular}

Tabela 5. Estimativas de correlação genética entre a arquitetura da planta e a produtividade de grãos das progênies $\mathrm{F}_{5: 6}, \mathrm{~F}_{5: 7}$ e $\mathrm{F}_{5: 8}$, oriundas de três populações segregantes de feijoeiro.

\begin{tabular}{lrcc}
\hline População & $\mathrm{F}_{5: 6}$ & $\mathrm{~F}_{5: 7}$ & $\mathrm{~F}_{5: 8}$ \\
\hline BRSMG Majestoso x BRS Horizonte & 0,24 & $0,68^{*}$ & $0,66^{*}$ \\
BRSMG Majestoso x BRS Supremo & 0,25 & $0,74^{*}$ & $-0,53$ \\
BRSMG Majestoso x BRS Valente & $-0,45$ & 0,58 & 0,34 \\
\hline
\end{tabular}

*Significativo a 5\% de probabilidade, pelo teste $\mathrm{t}$.

\section{Conclusões}

1. As respostas correlacionadas entre a seleção quanto ao porte de plantas de feijoeiro-comum e a produtividade de grãos e vice-versa são negativas, mas de pequena magnitude.

2. É possível selecionar simultaneamente progênies de feijoeiro-comum mais produtivas e com melhor arquitetura de plantas.

\section{Agradecimentos}

À Coordenação de Aperfeiçoamento de Pessoal de Nível Superior e ao Conselho Nacional de Desenvolvimento Científico e Tecnológico, pela concessão de bolsas.

\section{Referências}

ABREU, Â. de F.B.; DEL PELOSO, M.J.; RAMALHO, M.A.P.; CARNEIRO, J.E. de S.; PAULA JÚNIOR, T.J. de; PEREIRA FILHO, I.A.; MARTINS, M.; FARIA, L.C. de; MELO, L.C.; COSTA, J.G.C. da; RAVA, C.S.A.; SARTORATO, A.; FARIA, J.C. de; SILVA, H.T. da; BARROS, E.G. de; SANTOS, J.B. dos; MOREIRA, M.A. BRS 7762 Supremo: cultivar de feijão-comum de grão preto e porte ereto para Minas Gerais. Santo Antônio de Goiás: Embrapa Arroz e Feijão, 2008. 2p. (Embrapa Arroz e Feijão. Comunicado técnico, 160).

ALVES, G.F.; RAMALHO, M.A.P.; ABREU, Â. de F.B. Desempenho de cultivares antigas e modernas de feijão avaliadas em diferentes condições ambientais. Ciência e Agrotecnologia, v.25, p.863-870, 2001.

COLLICCHIO, E.; RAMALHO, M.A.P.; ABREU, Â. de F.B. Associação entre o porte da planta do feijoeiro e o tamanho dos grãos. Pesquisa Agropecuária Brasileira, v.32, p.297-304, 1997.

CUNHA, W.G. da; RAMALHO, M.A.P.; ABREU, Â. de F.B. Selection aiming at upright growth habit of common bean with carioca type grains. Crop Breeding and Applied Biotechnology, v.5, p.379-386, 2005.

DAWO, M.I.; SANDERS, F.E.; PILBEAM, D.J. Yield, yield components and plant architecture in the $\mathrm{F}_{3}$ generation of common bean (Phaseolus vulgaris L.) derived from a cross between the determinate cultivar 'Prelude' and an indeterminate landrace. Euphytica, v.156, p.77-87, 2007.

KNAPP, S.J.; STROUP, W.W.; ROSS, W.M. Exact confidence intervals for heritability on a progeny mean basis. Crop Science, v.25, p.192-194, 1985.

MENDES, F.F.; RAMALHO, M.A.P.; ABREU, Â. de F.B. Índice de seleção para escolha de populações segregantes do feijoeiro-comum. Pesquisa Agropecuária Brasileira, v.44, p.1312-1318, 2009.

MENEZES JÚNIOR, J.A.N.; RAMALHO, M.A.P.; ABREU, Â. de F.B. Seleção recorrente para três caracteres do feijoeiro. Bragantia, v.67, p.833-838, 2008. 
NIENHUIS, J.; SINGH, S.P. Combining ability analyses and relationships among yield, yield components and architectural traits in dry bean. Crop Science, v.26, p.21-27, 1986.

RAMALHO, M.A.P.; SANTOS, J.B. dos; ZIMMERMANN, M.J. de $\mathrm{O}$. Genética quantitativa aplicada em plantas autógamas: aplicações ao melhoramento do feijoeiro. Goiânia: UFG, 1993. $271 \mathrm{p}$.

SANTOS, J.B.; VENCOVSKY, R. Controle genético de alguns componentes do porte da planta em feijoeiro. Pesquisa Agropecuária Brasileira, v.21, p.957-963, 1986.

SILVA, V.M.P.; MENEZES JÚNIOR, J.A.N.; BARBOSA, R.M.; PEREIRA, A.C.; CARNEIRO, P.C.S.; CARNEIRO, J.E.S. Estimativas dos efeitos gênicos envolvidos no controle genético da arquitetura do feijoeiro. In: CONGRESSO NACIONAL DE
PESQUISA DE FEIJÃO, 9., 2008, Campinas. Ciência e tecnologia na cadeia produtiva do feijão: anais. Campinas: IAC, 2008. v.1, p.580-583.

SINGH, S.P.; GUTIERREZ, J.A.; MOLINA, A.; URREA, C.; GEPTS, P. Genetic diversity in cultivated common bean. II. Marker-based analysis of morphological and agronomic traits. Crop Science, v.31, p.23-29, 1991.

SAS INSTITUTE. SAS user's guide. Version 9.0. Cary: SAS Institute, 2000. 584p.

TEIXEIRA, F.F.; RAMALHO, M.A.P.; ABREU, Â. de F.B. Genetic control of plant architecture in the common bean (Phaseolus vulgaris L.). Genetics and Molecular Biology, v.22, p.577-582, 1999.

Recebido em 4 de maio de 2009 e aprovado em 20 de novembro de 2009 